\title{
Baboon placental heparin-binding epidermal growth factor-like growth factor
}

\author{
D Randall Armant ${ }^{1}$, Graham W Aberdeen², Brian A Kilburn' ${ }^{1}$, Gerald J Pepe ${ }^{3}$ and \\ Eugene D Albrecht ${ }^{2}$
}

${ }^{1}$ Department of Obstetrics and Gynecology, Wayne State University School of Medicine, Detroit, Michigan, USA, ${ }^{2}$ Departments of Obstetrics, Gynecology and Reproductive Sciences and Physiology, University of Maryland School of Medicine, Baltimore, Maryland, USA and ${ }^{3}$ Department of Physiological Sciences, Eastern Virginia Medical School, Norfolk, Virginia, USA

Correspondence should be addressed to E D Albrecht; Email: ealbrecht@som.umaryland.edu

\begin{abstract}
Placental extravillous trophoblast remodeling of the uterine spiral arteries is important for promoting blood flow to the placenta and fetal development. Heparin-binding EGF-like growth factor (HB-EGF), an EGF family member, stimulates differentiation and invasive capacity of extravillous trophoblasts in vitro. Trophoblast expression and maternal levels of HB-EGF are reduced at term in women with preeclampsia, but it is uncertain whether HB-EGF is downregulated earlier when it may contribute to placental insufficiency. A nonhuman primate model has been established in which trophoblast remodeling of the uterine spiral arteries is suppressed by shifting the rise in estrogen from the second to the first trimester of baboon pregnancy. In the present study, we used this model to determine if placental HB-EGF is altered by prematurely elevating estrogen early in baboon gestation. Uterine spiral artery remodeling and placental expression of HB-EGF and other EGF family members were assessed on day 60 of gestation in baboons treated with estradiol $\left(E_{2}\right)$ daily between days 25 and 59 of gestation (term $=184$ days). The percentages of spiral artery remodeling were 90,84 and $70 \%$ lower $(P<0.01)$, respectively, for vessels of 26-50, 51-100 and $>100 \mu \mathrm{m}$ diameter in $E_{2}$-treated compared with untreated baboons. HB-EGF protein quantified by immunocytochemical staining/image analysis was decreased three-fold $(P<0.01)$ in the placenta of $E_{2}$-treated versus untreated baboons, while amphiregulin (AREG) and EGF expression was unaltered. Therefore, we propose that HB-EGF modulates the estrogen-sensitive remodeling of the uterine spiral arteries by the extravillous trophoblast in early baboon pregnancy.

Reproduction (2020) 160 31-37
\end{abstract}

\section{Introduction}

Placental extravillous trophoblast invasion and remodeling of the uterine spiral arteries are thought to be critical for ensuring optimal maternal blood flow to the placenta and thus development of the fetus (Norwitz et al. 2001, Frank \& Kaufmann 2006). Failure of extravillous trophoblasts to invade and convert the spiral arteries to dilated conduits may hamper perfusion of the villous placenta and has been linked to preeclampsia (Brosens et al. 1972, DiFederico et al. 1999) and fetal growth restriction (Khong et al. 1986, Ishihara et al. 2002). Etiology of the defect in placentation that predisposes to preeclampsia or fetal growth restriction is unknown, but events occurring early in gestation that interfere with extravillous trophoblast survival, differentiation and/or uterine artery transformation are likely to be involved.

Although experimental animal models have been established which replicated the sequelae of maternal hypertension, proteinuria, and renal dysfunction symptomatic of human preeclampsia (McCarthy et al. 2011), these paradigms have not induced a defect in extravillous trophoblast remodeling of the uterine spiral arteries, a hallmark feature of preeclampsia. However, shifting the normal surge in maternal serum $\mathrm{E}_{2}$ levels from the second to the first trimester of baboon pregnancy suppressed extravillous trophoblast remodeling of the uterine spiral arteries and uteroplacental blood flow dynamics (Aberdeen et al. 2012, Bonagura et al. 2012). These authors have proposed, therefore, that the low levels of $E_{2}$ in the first trimester permit rapid transformation of the uterine arteries and the elevated levels of $E_{2}$ in the second trimester has a physiologically important role in suppressing and thus controlling the extent to which these vessels are remodeled. Prematurely elevating $E_{2}$ in early baboon pregnancy decreased placental vascular endothelial growth factor (VEGF) expression within the placental basal plate, that is, anchoring villi, trophoblastic shell and junctional zone (Bonagura et al. 2012), while VEGF gene delivery selectively to the placental basal plate 
restored spiral artery remodeling to normal (Babischkin et al. 2019). Therefore, it was proposed that VEGF mediates the estrogen-induced reduction in trophoblast spiral artery remodeling.

In vitro studies have shown that heparin-binding EGFlike growth factor (HB-EGF), a member of the EGF family that includes amphiregulin (AREG), prevents apoptosis within and stimulates differentiation and invasive capacity of extravillous trophoblast (Leach et al. 1999, Jessmon et al. 2009). HB-EGF is abundantly expressed by trophoblasts of the placental chorionic villi and basal plate and expression was significantly reduced at term in women with preeclampsia (Leach et al. 2002, Armant et al. 2015). However, it is uncertain whether HB-EGF is downregulated earlier in development when it may contribute to placental insufficiency or if dysregulation occurred later in gestation as a result of advanced disease. There appears to be a regulatory relationship between HB-EGF and VEGF, since HB-EGF increased VEGF expression in vitro by HTR-8/SVneo trophoblast (Liu et al. 2019) and granulosa (Karakida et al. 2011) cells; conversely, VEGF increased HB-EGF expression by umbilical vein vascular endothelial (Arkonac et al. 1998) and ocular (Inoue et al. 2018) cells. We hypothesize that dysregulation of HB-EGF, as well as VEGF, contributes to the reduced extravillous trophoblast invasion and transformation of the spiral arteries that occurs in human preeclampsia and that is induced by elevating estrogen in early baboon pregnancy. Therefore, placental expression of HB-EGF and related growth factors of the EGF signaling system and the level of spiral artery remodeling were assessed at the end of the first-third of gestation in baboons in which $\mathrm{E}_{2}$ levels were prematurely elevated.

\section{Materials and Methods}

\section{Animals}

Female baboons (Papio Anubis), originally obtained from the Southwest National Primate Research Center (San Antonio, TX) and weighing $13-15 \mathrm{~kg}$, were used in this study. Animals were housed individually in large primate cages and received standard monkey chow (Harlan Primate Diet, Madison, WI, USA) and fresh fruit twice daily, multiple vitamins daily, and water ad libitum. Females were paired with male baboons for 5 days at the time of ovulation, as estimated by menstrual cycle history and perineal turgescence, and day 1 of gestation was designated as the day preceding deturgescence. Baboons were cared for and used strictly in accordance with U.S. Department of Agriculture regulations and the National Institutes of Health Guide for the Care and Use of Laboratory Animals (National Academy Press, 2011). The experimental protocol was approved by the Institutional Animal Care and Use Committee of the University of Maryland School of Medicine.

A 2- to 4-mL blood sample was obtained from a maternal peripheral saphenous vein every 1-2 days during the study period from baboons after ketamine $\mathrm{HCl}$ sedation $(10 \mathrm{mg} / \mathrm{kg}$ body weight, im). Placentas were removed by cesarean section on day 60 of gestation (length of gestation is 184 days) from isoflurane-anesthetized baboons untreated $(n=5)$ or treated daily on days $25-59$ with $\mathrm{E}_{2}$ benzoate $(25 \mu \mathrm{g} / \mathrm{kg}$ body weight/ day, sc injection in $1.0 \mathrm{~mL}$ sesame oil, $n=5)$. At the time of cesarean section, blood samples $(1 \mathrm{~mL})$ were obtained from the left and right uterine veins. Serum $E_{2}$ levels were quantified using an automated chemiluminescent immunoassay system (Immulite; Diagnostic Products Corp., Los Angeles, CA, USA), as described previously (Albrecht et al. 2000). Serum HB-EGF levels were quantified by Quantikine ELISA (R\&D Systems).

\section{Quantification of uterine spiral remodeling}

At the time of cesarean section on day 60 , eight randomly selected areas of placental basal plate tissue were obtained and fixed in $10 \%$ formalin, embedded in paraffin, sectioned $(5 \mu \mathrm{m})$, microwaved in sodium citrate for antigen retrieval, and processed for hematoxylin and eosin histology and cytotrophoblast/epithelial cell-specific cytokeratin immunocytochemistry $(15 \mu \mathrm{g} / \mathrm{mL}$, mouse monoclonal, Cat No. 349205, BD Biosciences, San Jose, CA, USA), as described previously (Bonagura et al. 2012). Extravillous trophoblasts invade veins and lymphatic vessels, as well as arteries, in the first trimester of pregnancy (Windsperger et al. 2017, Moser et al. 2018, Huppertz 2019). Although cell-specific histochemical methods were not employed in the present study to identify these different vessel types, trophoblast intramural invasion of arteries, the criteria used to confirm vessel remodeling in baboons, exceeds that in veins and lymphatic vessels, whereas trophoblast intraluminal localization predominates in veins and lymphatic vessels (Windsperger et al. 2017, Moser et al. 2018). Moreover, trophoblast invasion of lymphatic vessels and veins appears more prevalent in early pregnancy, while trophoblast invasion and remodeling of the spiral arteries continues and becomes extensive in the latter stage of the first trimester, a time when vessel remodeling was analyzed in baboons of the current study. Therefore, the term spiral arteries is used throughout the present study.

The baboon placenta consists of approximately 20 cotyledons/placentomes (Houston \& Hendrickx 1968, Ramsey \& Donner 1980) each supplied via a single spiral artery. Light microscopy (Nikon Eclipse E 1000 M; Nikon) and an image analysis system (IP Laboratory, version 3.63; Scanalytics, Fairfax, VA, USA) were used to quantify trophoblast invasion/ remodeling in at least 12 of these spiral arteries randomly identified in each animal and categorize them into groups with diameters of 26 to 50,51 to 100 , and $>100 \mu \mathrm{m}$. The number of arteries exhibiting trophoblast invasion was quantified by identifying spiral arteries in which at least half of the vessel wall was occupied by cytokeratin-positive trophoblasts as illustrated in Fig. 1B. The level of uterine artery remodeling is expressed as the number of vessels exhibiting EVT invasion divided by the total number of vessels counted.

\section{Semiquantitative immunohistochemistry of $\mathrm{HB}-\mathrm{EGF}$}

Ten-micron sections were prepared from blocks of paraffinembedded placental tissue and mounted on microscope 
slides. Immunohistochemistry was performed using a DAKO Autostainer Universal Staining System (DAKO), as previously described (Leach et al. 2002, 2004, Imudia et al. 2008). Rehydrated sections were labeled for $1 \mathrm{~h}$ at $25 \mathrm{C}$ with either goat polyclonal antibody against human HB-EGF $(8 \mu \mathrm{g} / \mathrm{mL}$, Cat No. AF-259 E, R\&D Systems), amphiregulin (AREG, 10 $\mu \mathrm{g} / \mathrm{mL}$, Cat No. AF 262, R\&D Systems) or EGF $(10 \mu \mathrm{g} / \mathrm{mL}$, Cat No. MAB 236, clone 10825, R\&D Systems) or $10 \mu \mathrm{g} / \mathrm{mL}$ non-immunegoatlgG(Jackson Immunoresearch Laboratories). Tissues were then incubated for $1 \mathrm{~h}$ at $25^{\circ} \mathrm{C}$ with $0.1 \mu \mathrm{g} / \mathrm{mL}$ rabbit anti-goat IgG (Jackson Immunoresearch). To visualize and quantify antigen, an Envision System peroxidase antimouse/rabbit kit (DAKO) was used in conjunction with image analysis, according to our published procedure (Leach et al. 2002). Images obtained with a DM IRB inverted microscope (Leica) interfaced with an Orca digital camera (Hamamatsu, Hamamatsu City, Japan) were processed using Simple $\mathrm{PCl}$ software (Hamamatsu) to determine the mean gray level over designated regions of each image, according to our published procedure (Leach et al. 2002). Average values

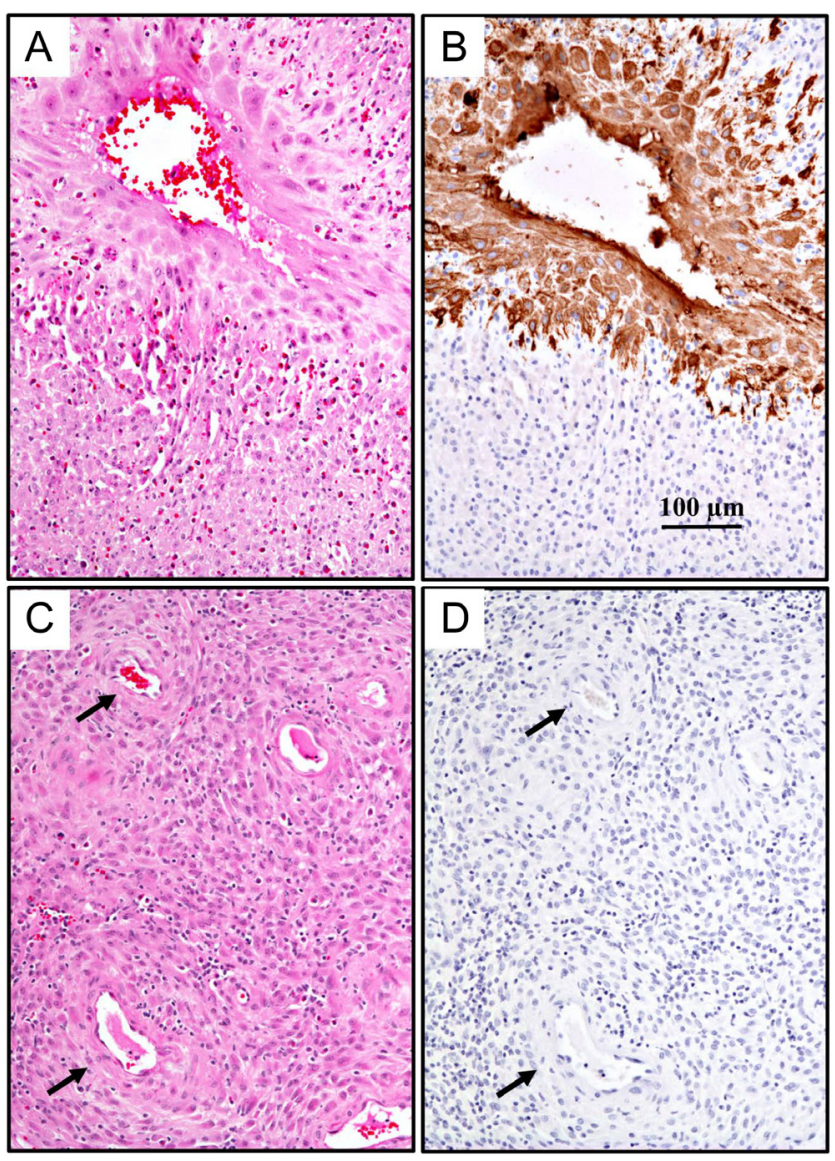

Figure 1 Photomicrographs of hematoxylin-eosin (panels A and C) and cytokeratin (panel B) stained extravillous trophoblasts within walls of uterine spiral arteries in the decidua basalis on day 60 of gestation in baboons untreated (panels $A$ and $B$ ) and $E_{2}$-treated (panels C and D) baboons. Magnification bar $=100 \mu \mathrm{m}$. Arrows, spiral arteries. obtained with IgG substituted for primary antibody were subtracted from each sample to determine the specific stain intensity. In a preliminary experiment, antibody was tittered using a human trophoblast HTR-8/SVneo cell line (Kilburn et al. 2000) to determine optimal concentration that gave robust staining within the linear portion of the concentration curve.

\section{Statistical analysis}

The levels of spiral artery remodeling and placental HB-EGF protein were analyzed by ANOVA followed by StudentNewman-Keuls test. Serum $E_{2}$ and fetal body and placental weights were analyzed by unpaired Student's $t$ test.

\section{Results}

\section{Serum $E_{2}$ and HB-EGF levels}

Maternal saphenous and uterine vein serum $E_{2}$ levels on day 60 of gestation were approximately five-fold $(0.74 \pm 0.07 \mathrm{ng} / \mathrm{mL})$ and two-fold $(1.21 \pm 0.16 \mathrm{ng} / \mathrm{mL})$ greater $(P<0.01)$, respectively, in the $\mathrm{E}_{2}$-treated compared to the untreated baboons (Table 1), but considerably lower than the level $(>2.0 \mathrm{ng} / \mathrm{mL})$ typical of the second trimester of normal baboon pregnancy (Albrecht et al. 2000). However, HB-EGF was not measurable in serum or plasma of the maternal saphenous or uterine veins of untreated and $\mathrm{E}_{2}$-treated baboons. Fetal body and placental weights on day 60 were unaltered by estrogen treatment (Table 1).

\section{Uterine spiral artery remodeling}

Figure 1 shows representative hematoxylin-eosin and cytokeratin stained extravillous trophoblasts within the walls of uterine spiral arteries in the decidua basalis on day 60 of baboon pregnancy. The striking invasion and remodeling by cytokeratin-stained extravillous trophoblasts of a spiral artery in an untreated baboon is shown in Fig. 1B. In contrast, the absence of cytokeratinstained trophoblasts within and tightly coiled nature of several spiral arteries of an $E_{2}$-treated baboon are illustrated in Fig. 1D.

Figure 2 shows the level of trophoblast invasion and remodeling of the uterine spiral arteries as quantified by image analysis on day 60 of gestation in the baboons of this study. In untreated baboons, the number of spiral arteries remodeled by trophoblasts, expressed as a ratio of the total number of vessels counted, was $5.4 \pm 1.1 \%$, $20.3 \pm 5.9 \%$ and $67.3 \pm 7.1 \%$, respectively, for arteries of 26-50, 51-100 and >100 $\mu \mathrm{m}$ in diameter. The percentages of spiral artery remodeling in the $E_{2}$-treated animals were $0.1 \pm 0.0 \%, 3.3 \pm 1.3 \%$ and $20.8 \pm 6.4 \%$ or $90 \%, 84 \%$ and $70 \%$, lower $(P<0.01)$ respectively, for the three different categories of vessels when compared with that in the untreated baboons. 
Table 1 Maternal estradiol and fetal body and placental weights in baboons.

\begin{tabular}{llccc}
\hline & & \multicolumn{2}{c}{ Estradiol $(\mathrm{ng} / \mathrm{mL})$} & \multirow{2}{*}{ Fetal body weight $(\mathrm{g})$} \\
\cline { 3 - 4 } & $\boldsymbol{n}$ & Saphenous vein & Uterine vein & Placental weight $(\mathrm{g})$ \\
\hline Untreated & 5 & $0.16 \pm 0.02$ & $0.70 \pm 0.06$ & $12.2 \pm 0.3$ \\
Estradiol & 5 & $0.74 \pm 0.07^{*}$ & $1.21 \pm 0.16^{*}$ & $11.6 \pm 0.6$ \\
\hline
\end{tabular}

Mean ( \pm S.E.) estradiol and fetal body and placental weights on day 60 of gestation in baboons untreated or administered estradiol benzoate $(25 \mu \mathrm{g} / \mathrm{kg}$ body weight/day, sc) daily on days $25-59$ of gestation (term $=184$ days).

$* P<0.01$ versus untreated baboons.

\section{Placental HB-EGF protein expression}

HB-EGF protein, as assessed by immunohistochemistry, in untreated baboons on day 60 of pregnancy was abundantly localized in the anchoring villi, cytotrophoblastic shell and decidua basalis of the placental basal plate (Fig. 3A and $\mathrm{A}^{\prime}$ ) and the trophoblast layer of the chorionic villi and inner villous core (Fig. $3 \mathrm{~B}$ and $\mathrm{B}^{\prime}$ ). However, in $\mathrm{E}_{2}$-treated baboons HB-EGF protein expression was negligible in the anchoring villi, cytotrophoblastic shell and decidua basalis (Fig. 3C and $\mathrm{C}^{\prime}$ ) and markedly reduced in the trophoblast layer covering the chorionic villi, although staining appear to be maintained in the inner villous core (Fig. 3D and $\mathrm{D}^{\prime}$ ).

HB-EGF protein immunostaining intensity, quantified by image analysis, was $60 \%$ lower $(P<0.01)$ in the placental basal plate of $E_{2}$-treated (8.6 \pm 1.9 units) compared with that in untreated $(23.5 \pm 3.5$ units) baboons (Fig. 4A). In contrast, AREG and EGF expression in the placental basal plate was not significantly different in untreated and $\mathrm{E}_{2}$-treated animals (Fig. 4A). In the placental chorionic villi, HB-EGF expression was $40 \%$ lower $(\mathrm{P}<0.05)$ in $\mathrm{E}_{2}$-treated $(14.9 \pm 2.3$ units) than in untreated $(25.3 \pm 4.9$ units) baboons (Fig. 4B). However, AREG and EGF immunostaining values in the chorionic villi were similar in untreated and $\mathrm{E}_{2}$-treated animals (Fig. 4B).

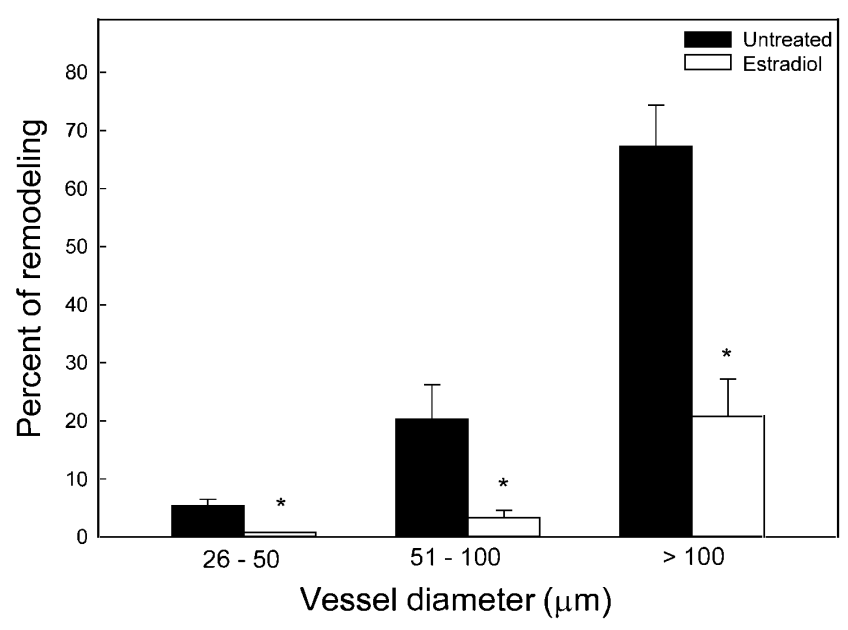

Figure 2 Percent of spiral artery remodeling (expressed as number of arteries exhibiting trophoblast invasion and remodeling divided by the total number of vessels counted) grouped by vessel diameter on day 60 in baboons untreated or treated daily on days 25-59 with $E_{2}$ benzoate. *Value different $(P<0.01)$ from untreated animals.

\section{Discussion}

The present study shows that in baboons in which serum $E_{2}$ levels were prematurely elevated in the first trimester of pregnancy, there was a decrease in placental basal plate and villous trophoblast expression of HB-EGF, along with suppression of trophoblast invasion and remodeling of the uterine spiral arteries. In contrast to the decline in placental HB-EGF, placental AREG and EGF expression was unaltered. HB-EGF expression in the placental basal plate is also significantly reduced at term in women with preeclampsia (Leach et al. 2002), a condition associated with failed physiologic conversion of the uterine spiral arteries (Brosens et al. 1972, Khong et al. 1986). HB-EGF is well established as a trophoblast survival factor (Armant et al. 2006, Wolff et al. 2007, Imudia et al. 2008, Leach et al. 2008), while both HB-EGF and EGF stimulate trophoblast invasion in vitro (Bass et al. 1994, Leach et al. 2004). The decrease in placental HB-EGF expression observed at term in women with preeclampsia may reflect an earlier attenuation of this growth factor which hampers trophoblast function and contributes to the pathology that arises during the second half of gestation in this disorder. Collectively, based on the present and previous findings we propose that dysregulation of HB-EGF early in development predisposes trophoblasts to cell death and reduced vessel invasion and thus modulates the estrogen-induced suppression of trophoblast remodeling of the uterine arteries in the baboon and improper placentation in human preeclampsia.

Placental extravillous VEGF mRNA and protein levels are also markedly decreased in baboons in which uterine spiral artery remodeling is suppressed by $E_{2}$ administration in early baboon pregnancy (Bonagura et al. 2012). Cross-talk between HB-EGF and VEGF pathways appears to exist, since VEGF increased HB-EGF expression by vascular endothelial (Arkonac et al. 1998) and ocular (Inoue et al. 2018) cells, while HB-EGF increased VEGF expression by HTR-8/SVneo trophoblast (Liu et al. 2019), granulosa (Karakida et al. 2011) and breast cancer (Yotsumoto et al. 2013) cells. Moreover, placental VEGF expression was decreased in fetal HB-EGF-knockout mice (Liu et al. 2019). Both VEGF and HB-EGF are potent endothelial mitogens and these growth factors may act synergistically in promoting proliferative and chemotactic responses (Gerritsen et al. 2003). 


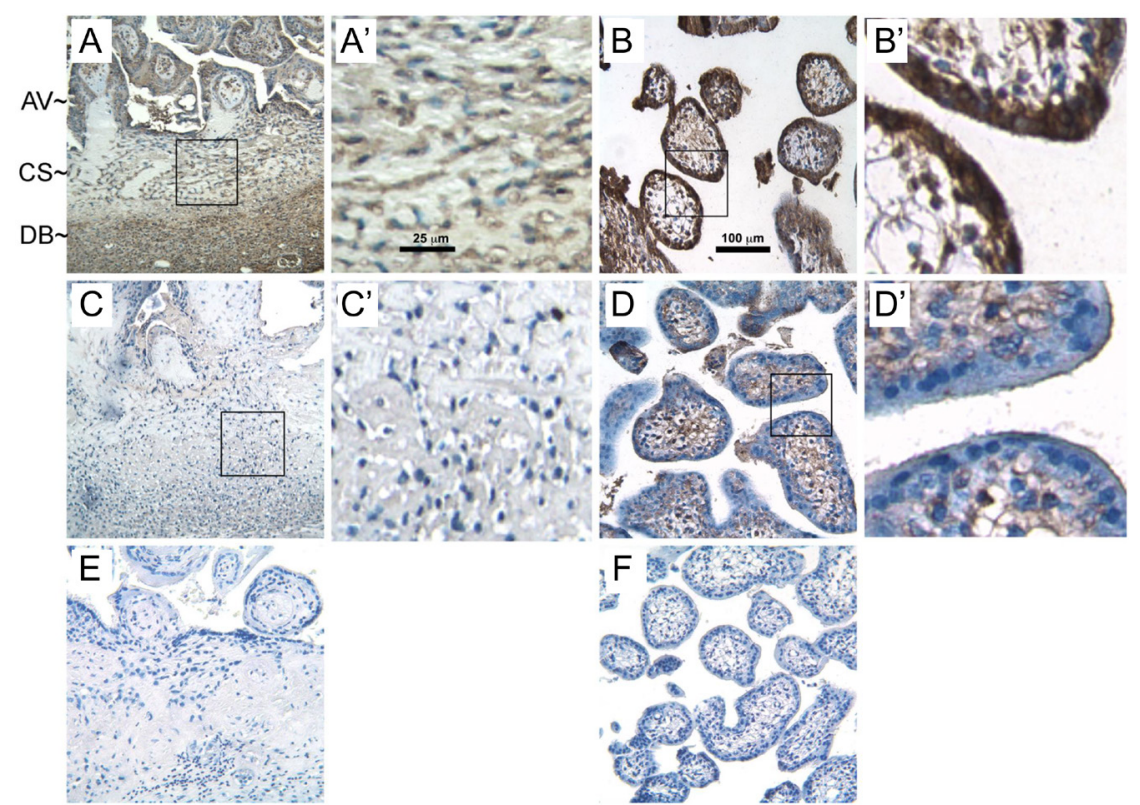

Figure 3 Immunohistochemical labeling of HB-EGF in anchoring villi (AV), cytotrophoblastic shell (CS) and decidua basalis (DB) of the placental basal plate (A, C and E) and the chorionic villi (B, D and $\mathrm{F}$ ) on day 60 of gestation in baboons untreated (A and $\mathrm{B})$ or treated with $\mathrm{E}_{2}(\mathrm{C}$ and $\mathrm{D})$. No labeling was apparent in placental sections when nonimmune IgG was substituted for anti-HB-EGF antibody ( $\mathrm{E}$ and $\mathrm{F}$ ). The areas within the boxes of panels $A-D$ are magnified as inserts in panels $A^{\prime}$ and $C^{\prime}$ to show a portion of the cytotrophoblastic shell and in panels $\mathrm{B}^{\prime}$ and $\mathrm{D}^{\prime}$ to show edges of chrionic villi.

$E_{2}$ either stimulates or inhibits the expression of VEGF and HB-EGF, depending on the specific tissue type (Wang et al. 1994, Zhang et al. 1994, Albrecht et al. 2004, Lee et al. 2004, Kanda \& Watanabe 2005). Consensus estrogen response elements do not appear to exist on the HB-EGF promoter, although induction of $\mathrm{HB}-\mathrm{EGF}$ expression by $\mathrm{E}_{2}$ in the uterus required activation of the estrogen receptor (Wang et al. 2002). Moreover, a link between HB-EGF/EGF receptor AKT-mTOR signaling with estrogen receptor $\alpha$ has been shown in the brain (Pandey et al. 2020) and $\mathrm{E}_{2}$ signaling to ErK-1/-2 stimulated $\mathrm{HB}$-EGF release by breast cells (Filardo et al. 2000). The $\mathrm{E}_{2}$-induced decrease in placental basal plate VEGF and HB-EGF in early baboon pregnancy may reflect the presence of estrogen receptor corepressors (Hu \& Lazar 2000, Yoon \& Wong 2006). The decrease in placental basal VEGF and HB-EGF expression with early $E_{2}$ treatment does not appear to be a consequence of the suppression of uterine spiral artery remodeling and blood flow. Thus, a decline in uterine artery blood flow does not emerge in $\mathrm{E}_{2}$-treated baboons until the second half of gestation (Aberdeen et al. 2012) and in contrast to the $\mathrm{E}_{2}$-induced decrease in placental basal plate VEGF and HB-EGF expression, AREG and EGF were unaltered and VEGF expression by trophoblasts in the chorionic villi was increased (Albrecht et al. 2004). Additional study is required to establish the potential interaction of VEGF and HB-EGF in modulating the action of $\mathrm{E}_{2}$ in regulating trophoblast spiral artery transformation in early pregnancy. The baboon provides a valuable nonhuman primate translational model to explore the relationship of signaling proteins to early placental development using in vivo experimental paradigms not possible to employ through human investigation.
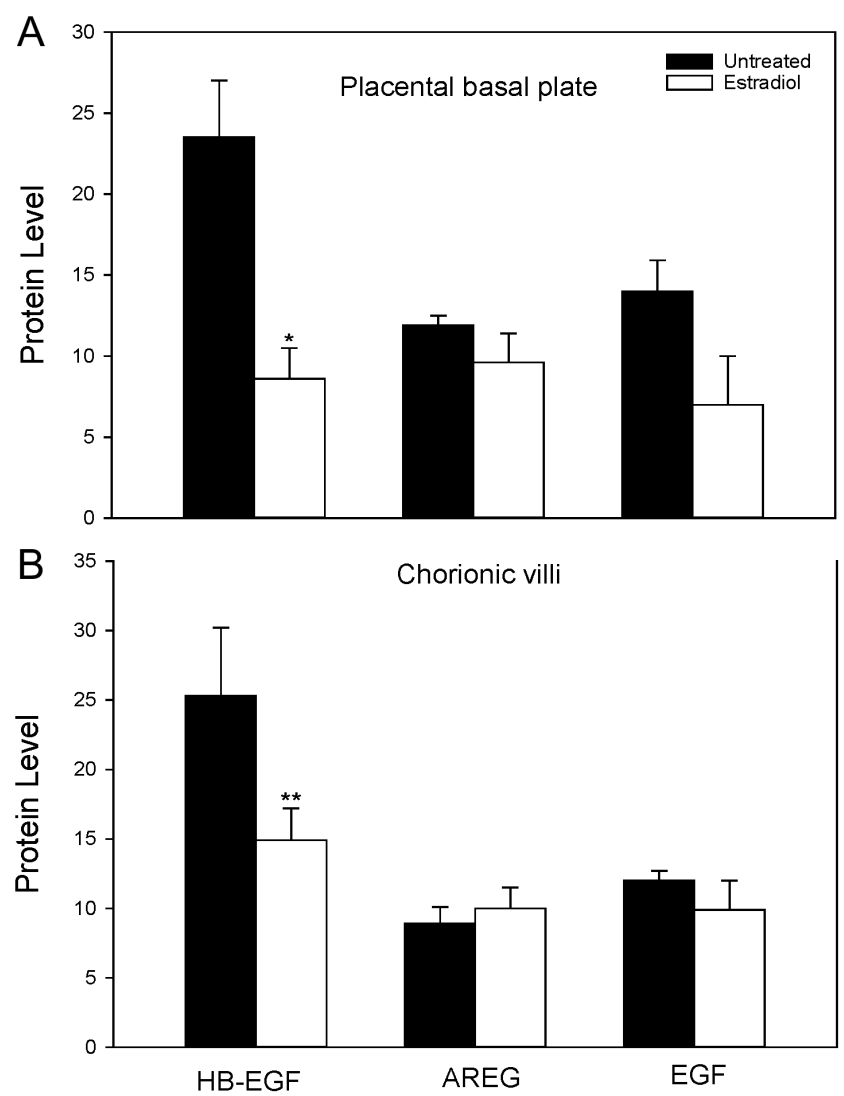

Figure 4 Quantitative assessment by image analysis of immunohistochemical staining of EGF family growth factors in placentas obtained on day 60 of gestation from baboons that were untreated or treated with $E_{2}$. Baboon placentas labeled with antibodies against HB-EGF, AREG, and EGF were imaged over the placental basal plate (A) and chorionic villi (B) and the level of staining (means \pm S.E.) for each protein (mean gray levels) was determined by image analysis, as described in the Methods section. ${ }^{*} P<0.01$ and ${ }^{* *} P<0.05$ versus values in untreated animals. 
In summary, the present study shows that placental basal plate expression of HB-EGF was decreased in baboons in which uterine spiral artery trophoblast invasion was suppressed by prematurely elevating $E_{2}$ levels in early pregnancy. Therefore, we suggest that dysregulation of HB-EGF early in pregnancy predisposes trophoblasts to reduced invasion and improper placentation.

\section{Declaration of interest}

The authors declare that there is no conflict of interest that could be perceived as prejudicing the impartiality of the research reported.

\section{Funding}

This work was supported by NIH R01 Research Grant HD 93070 (E D A and G J P) and NIH R01 Research Grant HD 45966 and Research Grant HD 071408 (D R A).

\section{Author contribution statement}

D R A and E D A conceived the study and wrote the paper. GW A performed the animal experiments and tissue analyses. B A $\mathrm{K}$ performed tissue analyses. G J P performed serum hormone analyses and collaborated with E D A on study design.

\section{Acknowledgement}

The authors appreciate the administrative assistance of Irene Baranyk at the University of Maryland School of Medicine with computer preparation of the manuscript.

\section{References}

Aberdeen GW, Bonagura TW, Harman CR, Pepe GJ \& Albrecht ED 2012 Suppression of trophoblast uterine spiral artery remodeling by estrogen during baboon pregnancy: impact on uterine and fetal blood flow dynamics. American Journal of Physiology: Heart and Circulatory Physiology 302 H1936-H1944. (https://doi.org/10.1152/ ajpheart.00590.2011)

Albrecht ED, Aberdeen GW \& Pepe GJ 2000 The role of estrogen in the maintenance of primate pregnancy. American Journal of Obstetrics and Gynecology 182 432-438. (https://doi.org/10.1016/s00029378(00)70235-3)

Albrecht ED, Robb VA \& Pepe GJ 2004 Regulation of placental vascular endothelial growth/permeability factor expression and angiogenesis by estrogen during early baboon pregnancy. Journal of Clinical Endocrinology and Metabolism 89 5803-5809. (https://doi.org/10.1210/jc.2004-0479)

Arkonac BM, Foster LC, Sibinga NES, Patterson C, Lait K, Tsai JC, Lee ME, Perrella MA \& Haber E 1998 Vascular endothelial growth factor induces heparin-binding epidermal growth factor-like growth factor in vascular endothelial cells. Journal of Biological Chemistry 273 4400-4405. (https://doi.org/10.1074/jbc.273.8.4400)

Armant DR, Kilburn BA, Petkova A, Edwin SS, Duniec-Dmuchowski ZM, Edwards HJ, Romero R \& Leach RE 2006 Human trophoblast survival at low oxygen concentrations requires metalloproteinase-mediated shedding of heparin-binding EGF-like growth factor. Development 133 751-759. (https://doi.org/10.1242/dev.02237)

Armant DR, Fritz R, Kilburn BA, Kilm YM, Nien JK, Naihle NJ, Romero R \& Leach RE 2015 Reduced expression of the epidermal growth factor signaling system in preeclampsia. Placenta 36 270-278. (https://doi. org/10.1016/j.placenta.2014.12.006)

Babischkin JS, Aberdeen GW, Lindner JR, Bonagura TW, Pepe GJ \& Albrecht ED 2019 Vascular endothelial growth factor delivery to placental basal plate promotes uterine artery remodeling in the primate. Endocrinology 160 1492-1505. (https://doi.org/10.1210/en.2019-00059)

Bass KE, Morrish D, Roth I, Bhardwaj D, Taylor R, Zhou Y \& Fisher SJ 1994 Human cytotrophoblast invasion is up-regulated by epidermal growth factor: evidence that paracrine factors modify this process. Developmental Biology 164 550-561. (https://doi.org/10.1006/ dbio.1994.1223)

Bonagura TW, Babischkin JS, Aberdeen GW, Pepe GJ \& Albrecht ED 2012 Prematurely elevating estradiol in early baboon pregnancy suppresses uterine artery remodeling and expression of extravillous placental vascular endothelial growth factor and $\alpha 1 \beta 1$ and $\alpha 5 \beta 1$ integrins. Endocrinology 153 2897-2906. (https://doi.org/10.1210/en.2012-1141)

Brosens IA, Robertson WB \& Dixon HG 1972 The role of the spiral arteries in the pathogenesis of preeclampsia. Obstetrics and Gynecology Annual 1 177-191.

DiFederico E, Genbacev O \& Fisher SJ 1999 Preeclampsia is associated with widespread apoptosis of placental cytotrophoblasts within the uterine wall. American Journal of Pathology 155 293-301. (https://doi. org/10.1016/S0002-9440(10)65123-1)

Filardo EJ, Quinn JA, Bland KI \& Frackelton Jr AR 2000 Estrogen-induced activation of Erk-1 and Erk-2 requires the G protein-coupled receptor homolog, GPR30, and occurs via trans-activation of the epidermal growth factor receptor through release of HB-EGF. Molecular Endocrinology 14 1649-1660. (https://doi.org/10.1210/mend.14.10.0532)

Frank HG \& Kaufmann P 2006 Nonvillous parts and trophoblast invasion. In Pathology of the Human Placenta, 5th ed., pp. 171-272. Eds K Benirschke \& P Kaufmann. New York: Springer Science+Business Media, Inc.

Gerritsen ME, Tomlinson JE, Zlot C, Ziman M \& Hwang S 2003 Using gene expression profiling to identify the molecular basis of the synergistic actions of hepatocyte growth factor and vascular endothelial growth factor in human endothelial cells. British Journal of Pharmacology 140 595-610. (https://doi.org/10.1038/sj.bjp.0705494)

Houston ML \& Hendrickx AG 1968 Observations on the vasculature of the baboon placenta (Papio sp) with special reference to the transverse communicating artery. Folia Primatologica: International Journal of Primatology 9 68-77. (https://doi.org/10.1159/000155168)

Hu X \& Lazar MA 2000 Transcriptional repression by nuclear hormone receptors. Trends in Endocrinology and Metabolism 11 6-10. (https:// doi.org/10.1016/s1043-2760(99)00215-5)

Huppertz B 2019 Traditional and new routes of trophoblast invasion and their implications for pregnancy diseases. International Journal of Molecular Sciences 21 289. (https://doi.org/10.3390/ijms21010289)

Imudia AN, Kilburn BA, Petkova A, Edwin SS, Romero R \& Armant DR 2008 Expression of heparin-binding EGF-like growth factor in term chorionic villous explants and its role in trophoblast survival. Placenta 29 784-789. (https://doi.org/10.1016/j.placenta.2008.06.013)

Inoue $Y$, Shimazawa $M$, Nakamura $S$, Takata $S$, Hashimoto $Y$, Izawa $H$, Masuda T, Tsuruma K, Sakaue T, Nakayama H et al. 2018 Both autocrine signaling and paracrine signaling of HB-EGF enhance ocular neovascularization. Arteriosclerosis, Thrombosis, and Vascular Biology 38 174-185. (https://doi.org/10.1161/ATVBAHA.117.310337)

Ishihara N, Matsuo H, Murakoshi H, Laoag-Fernandez JB, Samoto T \& Maruo T 2002 Increased apoptosis in the syncytiotrophoblast in human term placentas complicated by either preeclampsia or intrauterine growth retardation. American Journal of Obstetrics and Gynecology 186 158-166. (https://doi.org/10.1067/mob.2002.119176)

Jessmon P, Leach RE \& Armant DR 2009 Diverse functions of HB-EGF during pregnancy. Molecular Reproduction and Development $\mathbf{7 6}$ 1116-1127. (https://doi.org/10.1002/mrd.21066)

Kanda N \& Watanabe S $200517 \beta$-Estradiol enhances heparin-binding epidermal growth factor-like growth factor production in human keratinocytes. American Journal of Physiology: Cell Physiology 288 C813-C823. (https://doi.org/10.1152/ajpcell.00483.2004)

Karakida S, Kawano Y, Utsunomiya Y, Furukawa Y, Sasaki T \& Narahara H 2011 Effect of heparin-binding EGF-like growth factor and amphiregulin on the MAP kinase-induced production of vascular endothelial growth factor by human granulosa cells. Growth Factors 29 271-277. (https:// doi.org/10.3109/08977194.2011.607136) 
Khong TY, De Wolf F, Robertson WB \& Brosens I 1986 Inadequate maternal vascular response to placentation in pregnancies complicated by preeclampsia and by small-for-gestational age infants. British Journal of Obstetrics and Gynaecology 93 1049-1059. (https://doi. org/10.1111/j.1471-0528.1986.tb07830.x)

Kilburn BA, Wang J, Duniec-Dmuchowski ZM, Leach RE, Romero R \& Armant DR 2000 Extracellular matrix composition and hypoxia regulate the expression of HLA-G and integrins in a human trophoblast cell line. Biology of Reproduction 62 739-747. (https://doi.org/10.1095/ biolreprod62.3.739)

Leach RE, Khalifa R, Ramirez ND, Das SK, Wang J, Dey SK, Romero R \& Armant DR 1999 Multiple roles for heparin-binding epidermal growth factor-like growth factor are suggested by its cell specific expression during the human endometrial cycle and early placentation. Journal of Clinical Endocrinology and Metabolism 84 3355-3363. (https://doi. org/10.1210/jcem.84.9.5980)

Leach RE, Romero R, Kim YM, Chaiworapongsa T, Kilburn BA, Das SK, Dey SK, Johnson A, Qureshi F, Jacques S et al. 2002 Preeclampsia and expression of heparin-binding EGF-like growth factor. Lancet $\mathbf{3 6 0}$ 1215-1219. (https://doi.org/10.1016/S0140-6736(02)11283-9)

Leach RE, Kilburn B, Wang J, Liu Z, Romero R \& Armant DR 2004 Heparin-binding EGF-like growth factor regulates human extravillous cytotrophoblast development during conversion to the invasive phenotype. Developmental Biology $266 \quad 223-237 . \quad$ (https://doi. org/10.1016/j.ydbio.2003.09.026)

Leach RE, Kilburn BA, Petkova A, Romero R \& Armant DR 2008 Diminished survival of human cytotrophoblast cells exposed to hypoxia/ reoxygenation injury and associated reduction of heparin-binding epidermal growth factor-like growth factor. American Journal of Obstetric and Gynecology 198 471.e1-477.e1; discussion 471.e7-e8. (https://doi. org/10.1016/j.ajog.2008.01.009)

Lee JE, Chung KW, Han W, Kim SW, Kim SW, Shin HJ, Bae JY \& Noh DY 2004 Effect of estrogen, tamoxifen and epidermal growth factor on the transcriptional regulation of vascular endothelial growth factor in breast cancer cells. Anticancer Research 24 3961-3964.

Liu Z, Skafar DF, Kilburn B, Das SK \& Armant DR 2019 Extraembryonic heparin-binding epidermal growth factor-like growth factor deficiency compromises placentation in mice. Biology of Reproduction 100 217-226. (https://doi.org/10.1093/biolre/ioy174)

McCarthy FP, Kingdom JC, Kenny LC \& Walsh SK 2011 Animal models of preeclampsia: uses and limitations. Placenta 32 413-419. (https://doi. org/10.1016/j.placenta.2011.03.010)

Moser G, Windsperger K, Pollheimer J, Chuva de Sousa Lopes SC \& Huppertz B 2018 Human trophoblast invasion: new and unexpected routes and functions. Histochemistry and Cell Biology 150 361-370. (https://doi.org/10.1007/s00418-018-1699-0)

Norwitz ER, Schust DJ \& Fisher SJ 2001 Implantation and the survival of early pregnancy. New England Journal of Medicine 345 1400-1408. (https://doi.org/10.1056/NEJMra000763)
Pandey RM, Shukla P, Anjum B, Gupta HP, Pal S, Arjaria N, Gupta K, Chattopadhyah N, Sinha RA \& Bandyopadhyay S 2020 Estrogen deficiency induces memory loss via altered hippocampal HB-EGF and autophagy. Journal of Endocrinology 244 53-70. (https://doi. org/10.1530/JOE-19-0197)

Ramsey EM \& Donner MW 1980 Structure of the chorionic villi. In Placental Vasculature and Circulation, p. 31. Eds EM Ramsey \& MW Donner. Philadelphia: W.B. Saunders Company.

Wang XN, Das SK, Damm D, Klagsbrun M, Abraham JA \& Dey SK 1994 Differential regulation of heparin-binding epidermal growth factor-like growth factor in the adult ovariectomized mouse uterus by progesterone and estrogen. Endocrinology 135 1264-1271. (https://doi.org/10.1210/ endo.135.3.8070372)

Wang X, Wang H, Matsumoto H, Roy SK, Das SK \& Paria BC 2002 Dual source and target of heparin-binding EGF-like growth factor during the onset of implantation in the hamster. Development 129 4125-4134.

Windsperger K, Dekan S, Pils S, Golletz C, Kunihs V, Fiala C, Kristiansen G, Knöfler M \& Pollheimer J 2017 Extravillous trophoblast invasion of venous as well as lymphatic vessels is altered in idiopathic, recurrent, spontaneous abortions. Human Reproduction 32 1208-1217. (https:// doi.org/10.1093/humrep/dex058)

Wolff GS, Chiang PJ, Smith SM, Romero R \& Armant DR 2007 Epidermal growth factor-like growth factors prevent apoptosis of alcohol-exposed human placental cytotrophoblast cells. Biology of Reproduction 77 53-60. (https://doi.org/10.1095/biolreprod.106.057984)

Yoon HG \& Wong J 2006 The corepressors silencing mediator or retinoid and thyroid hormone receptor and nuclear receptor corepressor are involved in agonist and antagonist-regulated transcription by androgen receptor. Molecular Endocrinology 20 1048-1060. (https://doi. org/10.1210/me.2005-0324)

Yotsumoto F, Tokunaga E, Oki E, Maehara Y, Yamada H, Nakajima K, Nam SO, Miyata K, Kovanagi M, Doi K et al. 2013 Molecular hierarchy of heparin-binding EGF-like growth factor-regulated angiogenesis in triple-negative breast cancer. Molecular Cancer Research 11 506-517. (https://doi.org/10.1158/1541-7786.MCR-12-0428)

Zhang Z, Funk C, Roy D, Glasser S \& Mulholland J 1994 Heparinbinding epidermal growth factor-like growth factor is differentially regulated by progesterone and estradiol in rat uterine epithelial and stromal cells. Endocrinology 134 1089-1094. (https://doi.org/10.1210/ endo.134.3.8119147)

Received 15 October 2019

First decision 10 December 2019

Revised manuscript received 27 March 2020

Accepted 9 April 2020 